\title{
For whom the desert bell tolls: heat stroke or stroke
}

\author{
Mustafa Bolatkale ${ }^{1}$, Çağdaş Can ${ }^{2}$, Ahmet Çağdaş Acara ${ }^{3 *}$ \\ 'Department of Emergency Medicine, Medipol University Hospital, Istanbul, Turkey \\ ${ }^{2}$ Department of Emergency Medicine, Manisa State Hospital, Manisa, Turkey \\ ${ }^{3}$ Department of Emergency Medicine, Bitlis State Hospital, Bitlis, Turkey
}

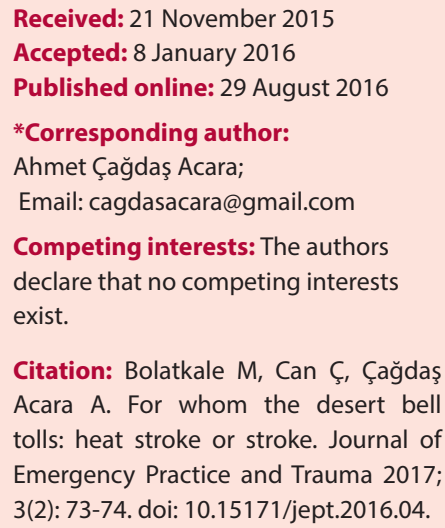

Received: 21 November 2015

Accepted: 8 January 2016

Published online: 29 August 2016

*Corresponding author:

Ahmet Çağdaş Acara;

Email: cagdasacara@gmail.com

Competing interests: The authors

declare that no competing interests

exist.

Citation: Bolatkale $M$, Can Ç, Çağdaş Acara A. For whom the desert bell tolls: heat stroke or stroke. Journal of Emergency Practice and Trauma 2017 3(2): 73-74. doi: 10.15171/jept.2016.04.

\begin{abstract}
Heat stroke is the most complicated and dangerous amongst heat injuries that can lead to irreversible injury and even death with itself or with creating predisposibility to different diseases. The following case report depicts a patient who presented primarily with impairment of consciousness after walking $45 \mathrm{~km}$ in the summer heat to cross the Syria-Turkey border and later syncope. This case report aims to highlight the possibility of higher co-incidence with heat stroke and stroke.

Keywords: Refugee, Stroke, Heat
\end{abstract}

\section{Introduction}

Heat stroke is a fatal illness with the plate-mark presentation of core body temperature greater than $40^{\circ} \mathrm{C}$ and impaired level of consciousness (1). Mortality has been reported to be as high as $50 \%$, and the illness is often misdiagnosed in the Emergency Department (ED) (2).

\section{Case Presentation}

A 46-year-old man was found having syncope on a hot summer day. The paramedics found him in SyriaTurkey border crossing. They injected an intravenous of normal saline prior to arrival and a finger stick revealed a blood glucose level of $136 \mathrm{mg} / \mathrm{dL}$. On arrival in the $\mathrm{ED}$, his temperature was $41.1^{\circ} \mathrm{C}\left(106^{\circ} \mathrm{F}\right)$, and the other vital signs were normal. He was moaning and flailing his arms and legs at staff. Depending on the patient's clinical status, supportive treatment may include administering supplemental oxygen, establishing adequate intravascular access, restoring intravascular volume with intravenous isotonic crystalloid solution, and placing a bladder catheter to monitor urine output. After treatment, the patient was afebrile and conscious and his general symptoms improved after 2 hours. The patient stated that he walked $45 \mathrm{~km}$ in the summer heat to cross the Syria-Turkey border and then lost consciousness. Ataxia was detected on patient's physical examination. Patient's laboratory values were in the normal range and normal sinus rhythm was detected on patient's electrocardiography (ECG). As patient's neurological symptoms continued despite treatment, he was taken for a brain tomography. There were no pathological findings on the patient's tomography, so for differential diagnosis, brain magnetic resonance imaging (MRI) was requested. MRI showed an acute cerebellar infarct in the left posterior inferior cerebellar artery territory (Figure 1). Hence, for this patient, in the absence of possible stroke time determination, we could not provide tPA thrombolysis. The patient was given aspirin (300 mg orally) and received consultation from a neurologist. He was admitted to the intensive care unit.

\section{Conclusion}

Heat stroke is distinguished from other heat illnesses by a loss of thermoregulation, tissue damage, and multiorgan failure. Classically, these patients are presented with hyperpyrexia and central nervous system dysfunctions (3). It is necessary to notice that heat stroke increases the

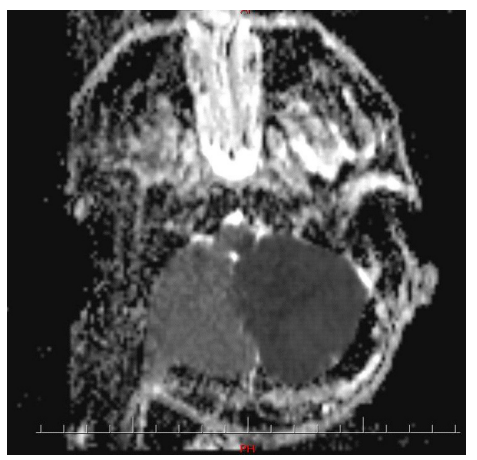

Figure 1. MRI showed an acute cerebellar infarct in the left posterior inferior cerebellar artery territory. 
incidence of stroke and for this reason investigations must be shaped in the light of this information.

\section{Ethical issues}

The authors declare no ethical issues.

\section{Authors' contributions}

All authors have equal portion to write this paper.

\section{References}

1. Gisi K, Koksal N, Sayarlıoglu M, Köroğlu S, Çiralik H. Heat Stroke caused by electric blanket: a rare surviving case. Turk J Emerg Med 2013; 13(2): 86-8. doi: 10.5505/1304.7361.2013.02259.

2. Lipman GS, Eifling KP, Ellis MA, Gaudio FG, Otten EM, Grissom CK, et al. Wilderness Medical Society Practice Guidelines for the Prevention and Treatment of HeatRelated Illness. Wilderness Environ Med 2013; 24(4): 35161. doi: 10.1016/j.wem.2013.07.004.

3. Glazer JL. Management of heatstroke and heat exhaustion. Am Fam Physician 2005; 71(11): 2133-40. 